\title{
Microstructure Evolution of a Cold-rolled 25Cr-7Ni-3Mo-0.2N Duplex Stainless Steel during Two-step Aging Treatments
}

\author{
Tian LIANG, Xiaoqiang HUं, Xiuhong KANG and Dianzhong LI \\ Shenyang National Laboratory for Materials Science, Institute of Metal Research, Chinese Academy of Sciences, Shenyang \\ 110016, China
}

[Manuscript received 10 April 2013, in revised form 3 May 2013]

(C) The Chinese Society for Metals and Springer-Verlag Berlin Heidelberg

\begin{abstract}
A cold-rolled $25 \mathrm{Cr}-7 \mathrm{Ni}-3 \mathrm{Mo}-0.2 \mathrm{~N}$ duplex stainless steel (DSS) has been aged in two steps. Firstly, the aging treatment at interval of $50{ }^{\circ} \mathrm{C}$ in a temperature range from 900 to $1050{ }^{\circ} \mathrm{C}$ was carried out in order to obtain fine grains. Secondly, another aging treatment at $850{ }^{\circ} \mathrm{C}$ was performed to reveal the $\sigma$-phase precipitation behavior. A detailed microstructure evolution during those two aging steps was observed by the optical microscope (OM), the scanning electron microscope (SEM), the electron backscatter diffraction (EBSD) and the transmission electron microscope (TEM). The results revealed that the micro-duplex structure with grain size of lower than $10 \mu \mathrm{m}$ appeared after the first aging step. However, their grain size was rapidly increased with increasing aging temperature. Meanwhile, the $\delta \rightarrow \gamma$ and/or $\delta \rightarrow \gamma+\sigma$ transformations took place in association with the occurrence of the extensive recovery or a little recrystallization in $\delta$-grains. During the second aging treatment, $\sigma$-phase mainly nucleated at $\delta / \gamma$ interfaces and further grew along those interfaces into various morphologies (e.g., butterfly and granule). A novel precipitation behavior was found in this study that the $\gamma$-grain boundaries bulged not only into the $\delta$-grains as usual, but abnormally into the $\sigma$-phase precipitates without the prior precipitation of the isolated secondary austenite $\gamma_{2}$ or another phases.
\end{abstract}

\section{KEY WORDS: Duplex stainless steel; Microstructure evolution; Sigma phase; Aging treatment; Micro-duplex structure}

\section{Introduction}

Duplex stainless steels (DSS) with the approximately equal percent of $\delta$ and $\gamma$ phases have advantages of a combination of excellent mechanical properties and sound corrosion resistance. This kind of steels is utilized to make containers and pipes for storage and transportation of oil and gas, some important parts for service in the ocean environment, essential components in nuclear power plants and so on ${ }^{[1-4]}$.

As well known, the DSS exposed in temperature range from $600{ }^{\circ} \mathrm{C}$ to $1000{ }^{\circ} \mathrm{C}$ becomes much brittle due to formation of some intermetallic phase precipitations $^{[5,6]}$. The $\sigma$-phase is a main factor to lower the toughness and corrosion resistance. In 2205

\footnotetext{
† Corresponding author. Assist. Prof., Ph.D.; Tel.: +86 24 23971127; Fax: +86 24 83970097; E-mail address: xqhu@imr.ac.cn (Xiaoqiang HU)
}

DOI: $10.1007 / \mathrm{s} 40195-013-0210-0$
DSS after solution treated at $1050{ }^{\circ} \mathrm{C}$, less than five volume percent of $\sigma$-phase could damage the toughness from about $250 \mathrm{~J}$ to $10 \mathrm{~J}$ or less ${ }^{[7-9]}$. Additionally, the Cr- and Mo-rich $\sigma$-phase results in the depletion of corresponding elements, which decreases the average and crevice corrosion resistance ${ }^{[10,11]}$. Two different mechanisms of $\sigma$-phase precipitation in DSS have been reported in previous literatures. Firstly, $\sigma$-phase is believed to nucleate directly at the interfaces between $\delta$-phase and $\gamma$-phase, and then grow rapidly into $\delta$ grains by the solute repartition by consuming $\mathrm{Cr}$ and $\mathrm{Mo}$ as well as discharging Ni. The solute repartition makes $\delta$ unstable and subsequently decomposed into the secondary austenite $\gamma_{2}$, abiding by the eutectoid reaction $\delta \rightarrow \gamma_{2}+\sigma^{[12-14]}$. Hence, the morphologies of $\sigma$-phase often present in eutectic character with lamellar and lacing shapes. Secondly, $\sigma$-phase could nucleate at a new interface between $\delta$ and the secondary austenite $\gamma_{2}$ which is induced by the prior precipitation of carbides or some metallic 


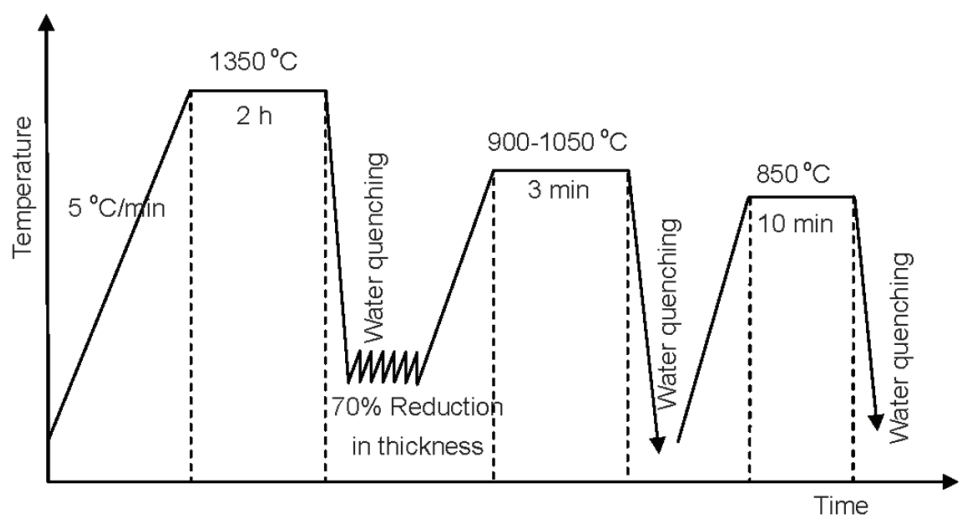

Fig. 1 Schematic of the thermo-mechanical processes for DSS

compounds ${ }^{[7,15]} \cdot \sigma$-phase grows with morphologies in bulk or butterfly alongside $\gamma_{2}$ into the $\delta$ grains.

Therefore, the control of the $\sigma$-phase precipitation in DSS is usually considered as a key issue to obtain good properties. Many researchers have put emphasis on the suspension of sigma phase precipitation through adjusting alloy element content ${ }^{[16-18]}$ or heat-treatment parameters ${ }^{[19,20]}$. But, some work lately indicated that the $\sigma$-phase could significantly enhance the superplasticity of the DSS with the micro duplex structure by a proper thermomechanical processes ${ }^{[21-23]}$. However, there are still few reports on the microstructure evolution during the aging treatment of the micro-duplex structure.

In order to reveal and understand the microstructure evolution, especially the $\sigma$-phase precipitation behavior in the micro-duplex structure during aging treatment, two-step aging treatments were carried out in the present work. At first, the microduplex structure in a cold-rolled $25 \mathrm{Cr}-7 \mathrm{Ni}-3 \mathrm{Mo}-0.2 \mathrm{~N}$ DSS was achieved by aging treatment in a temperature range from 900 to $1050{ }^{\circ} \mathrm{C}$. And then, the other aging treatment at $850{ }^{\circ} \mathrm{C}$ was subsequently carried out to further investigated on the $\sigma$-phase precipitation behavior in the micro-duplex structure.

\section{Experimental}

The experimental samples of a duplex stainless steel were about $5 \mathrm{~mm}$ in thickness machined from a large impeller casting for nuclear power plants. The chemical composition (wt.\%) contains $0.032 \mathrm{C}, 0.96$ $\mathrm{Mn}, 0.52 \mathrm{Si}, 0.026 \mathrm{P}, 0.0063 \mathrm{~S}, 25.75 \mathrm{Cr}, 6.78 \mathrm{Ni}$, $2.68 \mathrm{Mo}, 0.18 \mathrm{~N}, 0.42 \mathrm{Cu}$ and bal. Fe. The initial microstructure of the sample with very coarse grain sizes comprises about $43 \mathrm{vol} . \% \delta$-phase and 57 vol. $\% \gamma$ phase. In order to refine these coarse grains, $70 \%$ cold rolling reduction at room temperature was performed after solution treatment at $1350{ }^{\circ} \mathrm{C}$ for $2 \mathrm{~h}$. And then, two-step aging treatments with subsequent water quenching were carried out in order to obtain fine grains and reveal the $\sigma$-phase precipitation behavior.
The cold-rolled samples were firstly aged at interval of $50{ }^{\circ} \mathrm{C}$ in a temperature range from $900{ }^{\circ} \mathrm{C}$ to $1050{ }^{\circ} \mathrm{C}$ for $3 \mathrm{~min}$ and secondly at $850{ }^{\circ} \mathrm{C}$ for $10 \mathrm{~min}$, which is shown in Fig. 1.

All the aging treatments were carried out in the same experimental electric furnace. The microstructures of the samples after the solution treatment, cold rolling and two-step aging treatments were analyzed by the optical microscope (OM, Leica), scanning electron microscope (SEM, Hitachi S-3400N), electron backscatter diffraction (EBSD, the software of Channel 5) and transmission electron microscope (TEM, FEI F20). The specimens after mechanical polishing for the observation in OM, SEM of and EBSD as well were prepared by an electrolytic etching technique in a solution of $20 \mathrm{~g} \mathrm{KOH}+100 \mathrm{~mL} \mathrm{H}_{2} \mathrm{O}$. Thin foils for TEM analysis were etched by a twin-jet machine (Struers Tenupol-5) in a solution of $10 \% \mathrm{HClO}_{4}$ $+\mathrm{CH}_{5} \mathrm{OH}$ at temperature of $-20{ }^{\circ} \mathrm{C}$ below and under $20 \mathrm{~V}$.

\section{Results and Discussion}

\subsection{Microstructure evolution}

Figs. 2(a) and Fig. 2(b) show the optical micrographs of the DSS after solution treatment at $1350{ }^{\circ} \mathrm{C}$ for $2 \mathrm{~h}$ under water quenching and cold rolling at room temperature, respectively. It can be seen that most $\gamma$-phase in Widmanstäten morphology up to $1 \mathrm{~mm}$ in length alongside the $\delta$-grain boundaries occupies about $15 \%$ in volume in the coarse $\delta$-phase matrix because of the high solution treatment temperature. A little fraction of the $\gamma$-phase in island-like morphology indicated by arrows in Fig. 2a could also be observed as large size with about $10 \mu \mathrm{m}$ in width and $50 \mu \mathrm{m}$ in length. After cold rolling at room temperature, the amount of $\gamma$-phase remains unchanged. However, both the size of $\gamma$-grains and its morphologies were varied. The $\gamma$-phase is much smaller in the aligned island-like shape, which was elongated in the cold rolling direction, as shown in Fig. 2(b). 


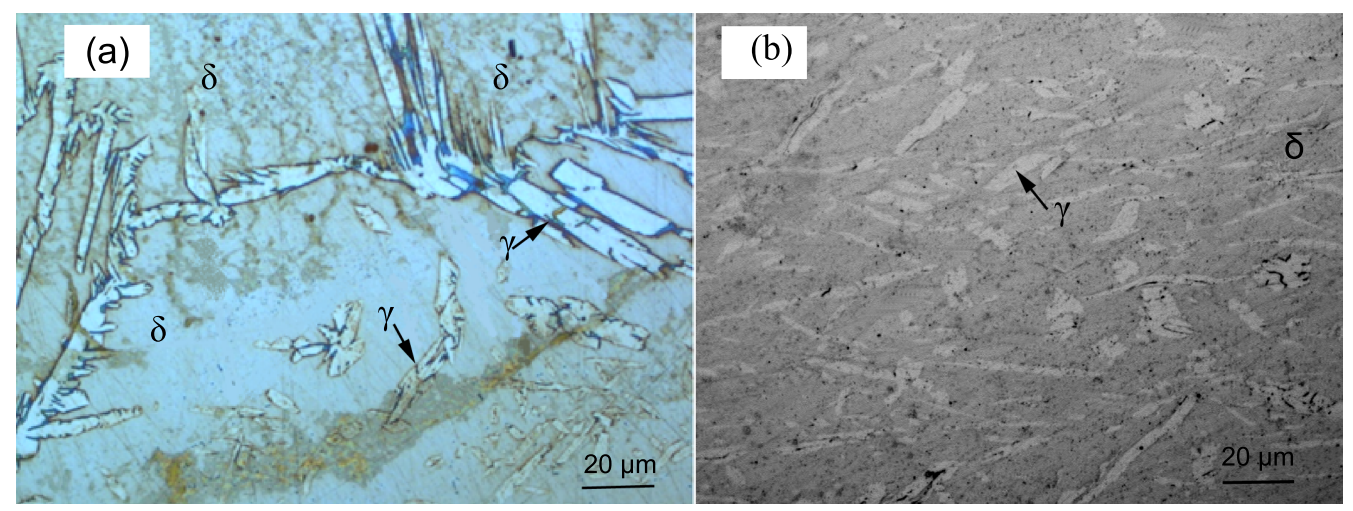

Fig. 2 Optical micrographs of the studied DSS after solution treatment at $1350{ }^{\circ} \mathrm{C}$ for $2 \mathrm{~h}(\mathrm{a})$ and cold rolling at room temperature (b)

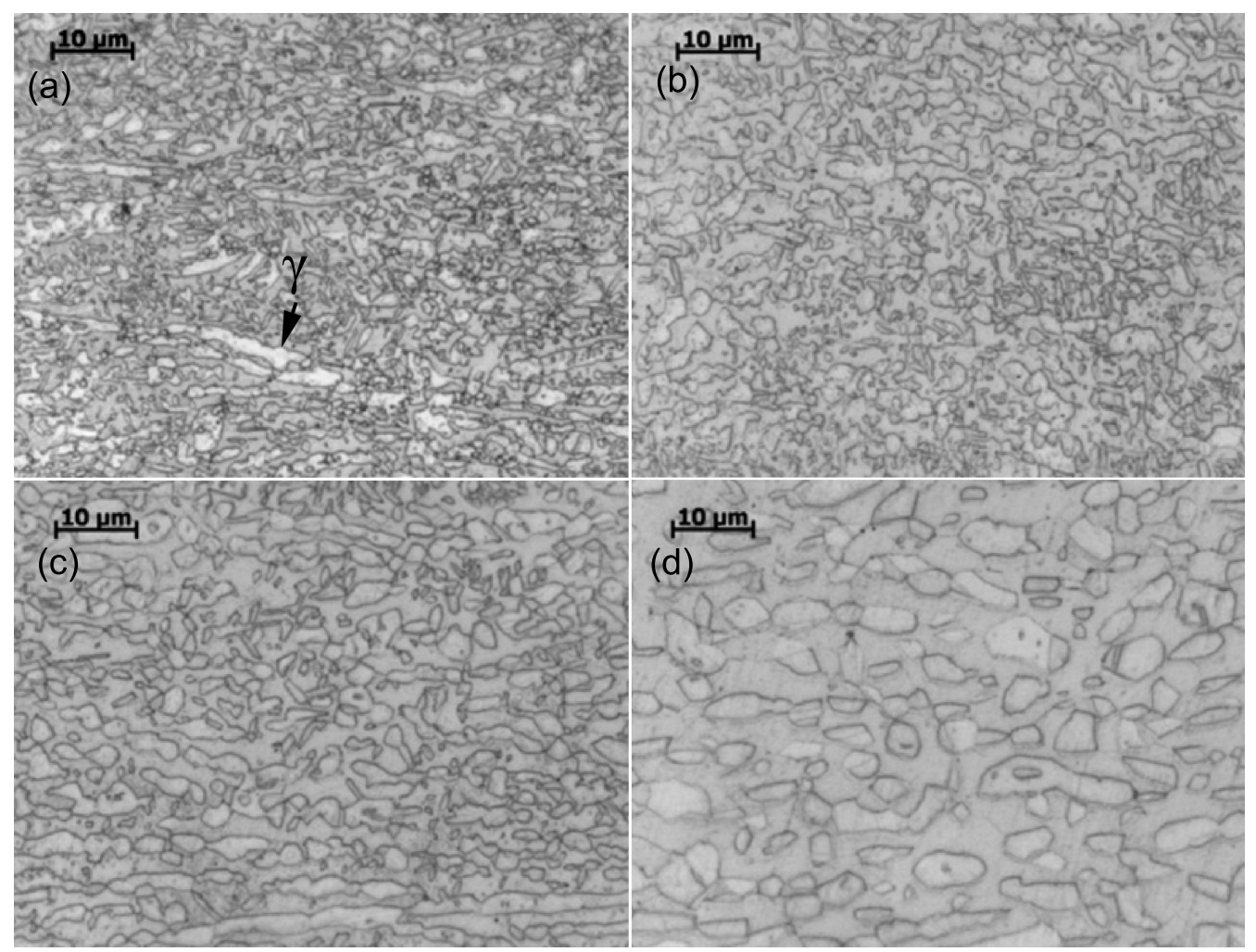

Fig. 3 Optical micrographs of the cold-rolled DSS aged at $900{ }^{\circ} \mathrm{C}(\mathrm{a}), 950{ }^{\circ} \mathrm{C}(\mathrm{b}), 1000{ }^{\circ} \mathrm{C}(\mathrm{c})$, and $1050{ }^{\circ} \mathrm{C}(\mathrm{d})$ for $3 \mathrm{~min}$, respectively. The gray, pink and black correspond to the $\delta$-phase, $\gamma$-phase and $\sigma$-phase

Fig. 3 shows the optical micrographs of the coldrolled DSS and subsequently aged at 900, 950, 1000 and $1050{ }^{\circ} \mathrm{C}$ for $3 \mathrm{~min}$, respectively. The micro-duplex structure with very fine equiaxed $\gamma$-phase and $\delta$-phase grains smaller than $10 \mu \mathrm{m}$ was obtained. No islandlike $\gamma$-phase as indicated by arrow in Fig. 3(a) was observed in the $\delta$-phase matrix except for the aging at $900{ }^{\circ} \mathrm{C}$. And the amount of the $\gamma$-phase remains almost the same to that of $\delta$-phase, as the aging temperature increases from $900{ }^{\circ} \mathrm{C}$ to $1050{ }^{\circ} \mathrm{C}$. A very small fraction of $\sigma$-phase precipitates colored in black in Fig. 3(a) and Fig. 3(b) appears at grain boundaries between $\delta$-phase and $\gamma$-phase when the aging tem- perature is lower than $950{ }^{\circ} \mathrm{C}$. The size of $\gamma$-grains grows rapidly from $2-4 \mu \mathrm{m}$ up to around $10 \mu \mathrm{m}$ as the aging temperature is increased from $950{ }^{\circ} \mathrm{C}$ to $1050{ }^{\circ} \mathrm{C}$. These results obviously demonstrate that the $\delta \rightarrow \gamma$ or the $\delta \rightarrow \gamma+\sigma$ transformation occurs in such a way to enhance the amount of the $\gamma$-phase up to about 50 vol.\% during the aging treatment, rather than 15 vol.\% after the cold rolling at room temperature in Fig. 2(b). Recrystallization might occur within the $\delta$-grains such that the $\delta$-grains are refined into the equiaxed morphologies, while the aligned island-like $\gamma$-grains marked by arrows in Fig. 2(b) become spherical quickly if the aging temperature is over $950{ }^{\circ} \mathrm{C}$. 
Fig. 4(a) is the orientation imaging micrograph by EBSD mapping in a step size of $0.3 \mu \mathrm{m}$ for the cold-rolled DSS aged at $1000{ }^{\circ} \mathrm{C}$. Both $\delta$-grains in red and $\gamma$-grains in green tend equiaxed. But, the $\delta$-grain size is very inhomogeneous. Some $\delta$-grains are smaller than $1 \mu \mathrm{m}$ along $\gamma$-grain boundaries alone. Otherwise, most of the other larger $\delta$-grains gather to form the cluster with a diameter of $5 \mu \mathrm{m}$. Fig. 4(b) shows the $\delta$-grain boundary misorientation in a statistical histogram. The misorientation angle of $\delta$-grain boundaries lies mainly in $3^{\circ}-13^{\circ}$ less than $15^{\circ}$ as the value dividing small angle boundaries from big ones. It is believed that the extensive recovery within $\delta$-grains occurs. A small continuous frequency of the misorientation angle between $50^{\circ}$ and $53^{\circ}$ has been also observed in Fig. 4(b). This might refer to the remained initial $\delta$-grains not completely transforming into $\gamma$ grains (mentioned above) or the occurrence of some recrystallization. It is very complex that the strain partitioning between $\delta$ - and $\gamma$-grains is not homogeneous during the cold rolling process. $\delta$-grains could accommodate much less strain than $\gamma$-grains, because of their higher strength and lower ductility at room temperature. Thus, the dislocation density in $\delta$-grains might much lower. Moreover, the stacking fault energy of $\delta$-grains is much higher, which dictates the tendency to recovery during the aging treatment at $1000{ }^{\circ} \mathrm{C}$. However, a little recrystallization nuclei of $\delta$-grains may be formed on some boundaries or shear bands with dislocation piling-up ${ }^{[22]}$.

\subsection{The precipitation mechanism of $\sigma$-phase in the micro-duplex structure}

Fig. 5 shows SEM images of the microstructure consisting of micro-duplex structure $(\delta$-grains in black and $\gamma$-grains in gray, respectively) and $\sigma$-phase precipitates in white. The fine equiaxed $\delta$ - and $\gamma$-grains of micro duplex structure obtained during the first aging treatment could be remained even after the second aging treatment at $850{ }^{\circ} \mathrm{C}$. A large amount of $\sigma$-phase precipitates distribute along the $\delta / \gamma$ interfaces. These
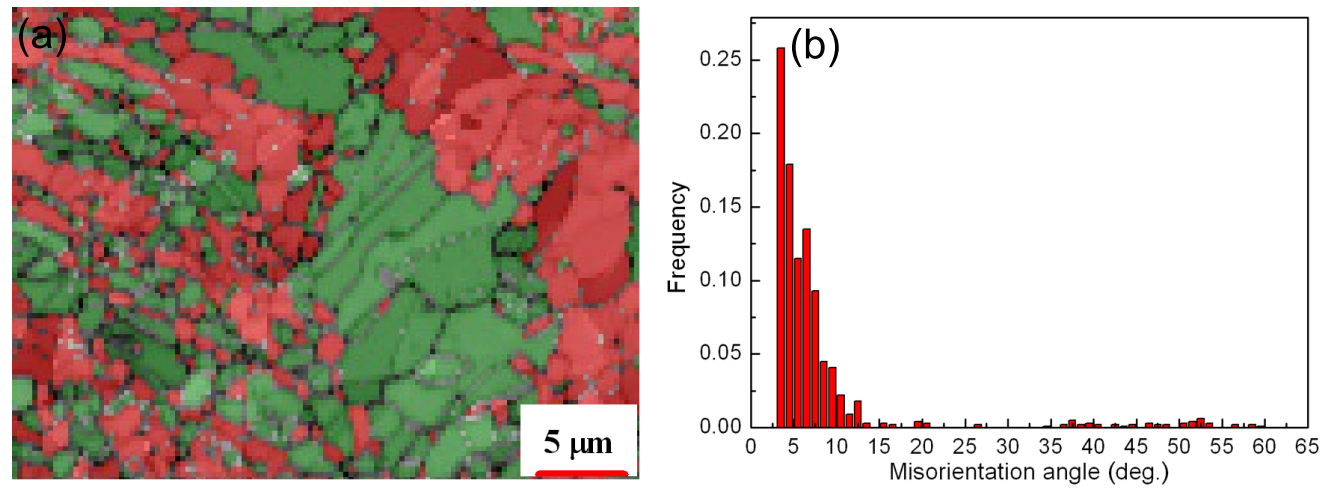

Fig. 4 Orientation imaging micrograph by EBSD for the cold-rolled DSS aged at $1000{ }^{\circ} \mathrm{C}$ (a) and the statistical histogram of the grain boundary misorientation among $\delta$-grains (b), which reveals recovery and recrystallization in $\delta$-phase during aging treatment. The red and green regions in Fig. 4(a) are corresponding to the $\delta$-grains and $\gamma$-grains, respectively

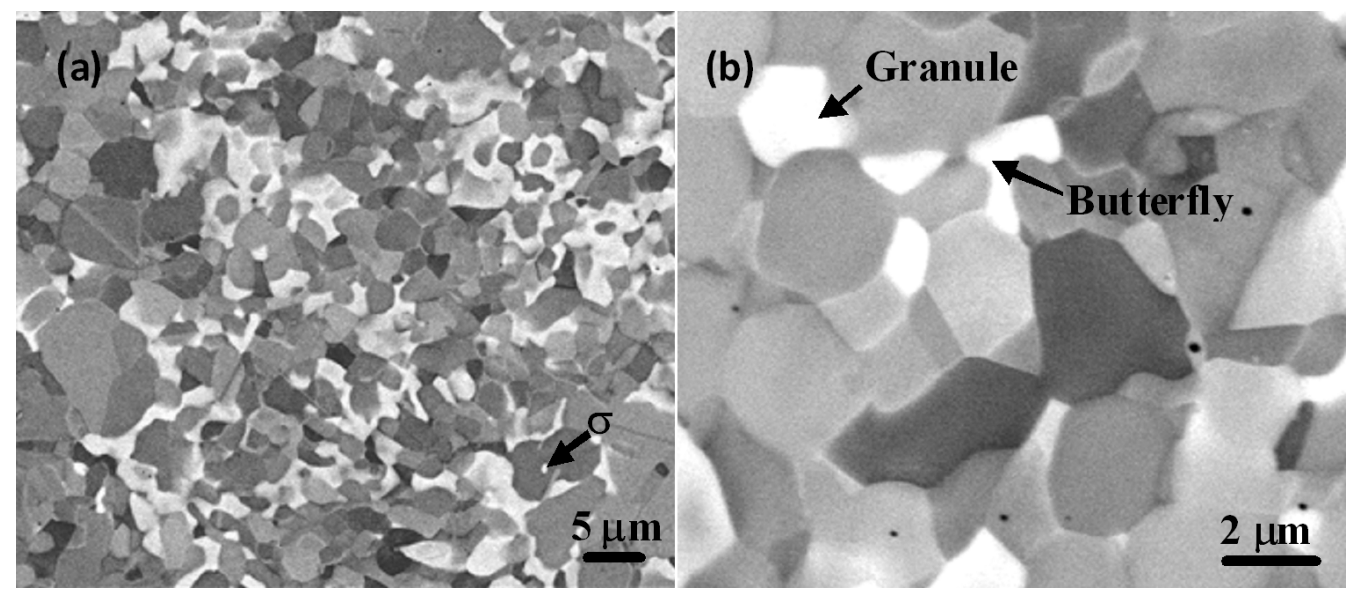

Fig. 5 SEM images for the cold-rolled DSS after the second aging treatment at $850{ }^{\circ} \mathrm{C}$ showing microstructure of $\sigma$-phase in white, $\gamma$-phase in gray and $\delta$-phase in black (a), and to demonstrate the morphologies and distribution of $\sigma$-phase in magnification (b) 
precipitates have grown up alongside the interfaces in consumption of $\delta$-grains, which makes $\sigma$ precipitates in various morphologies of granule and butterfly dependent upon the growing extent as shown in Fig. $5(\mathrm{~b})$, respectively. Some fine $\gamma$ - and $\delta$-grains were surrounded by many $\sigma$-phase precipitates. Unexpectedly, neither eutectic character of the $\sigma$-phase morphologies nor carbides have been observed. And several $\sigma$ precipitates in nanoscale also appear at $\delta$-grain boundaries, as marked by arrows in Fig. 5(a). These results suggest that the precipitation mechanism of $\sigma$ phase in the micro-duplex structure is a little different from previous reports ${ }^{[12-15]}$. This behavior might be caused by a great amount of interfaces and boundaries which serve as the rapid diffusion paths in the very fine micro duplex structure. Elements rich in $\sigma$ phase, such as $\mathrm{Cr}$ and Mo, could be quickly enriched up to a critical concentration required for the precipitation of $\sigma$-phase. The $\sigma$-phase precipitates could directly nucleate without the induction of carbides or metal compounds at interface between $\delta$-phase and $\gamma$-phase. However, it is difficult to understand the $\sigma$ phase precipitates at the $\delta$-grain boundaries, as shown in Fig. 5(a).

Fig. 6 shows the TEM micrograph for the coldrolled DSS after the second aging treatment at $850^{\circ} \mathrm{C}$. Some granular $\sigma$-phase precipitates which less than 1 $\mu \mathrm{m}$ have been observed distributing alone at the $\gamma$ grain boundaries. The $\delta$-grains at $\gamma$-grain boundaries remain in nanoscale owing to the uncompleted decomposition for the $\sigma$-phase precipitation and $\gamma$-phase transformation, which is consistent with the results of EBSD orientation imaging micrograph above. The $\gamma$ grain boundaries bulge not only into $\delta$-grains as usual, but also abnormally into the $\sigma$-phase precipitates (see arrows in Fig. 6). No isolated austenite $\gamma_{2}$ has been observed. This result reveals that the $\sigma$-phase might occupy the whole $\delta$-grain. And the discharge of some elements rich in the $\gamma$-phase from $\sigma$-phase precipitates favors the fact that $\gamma$-grain boundaries bulge into

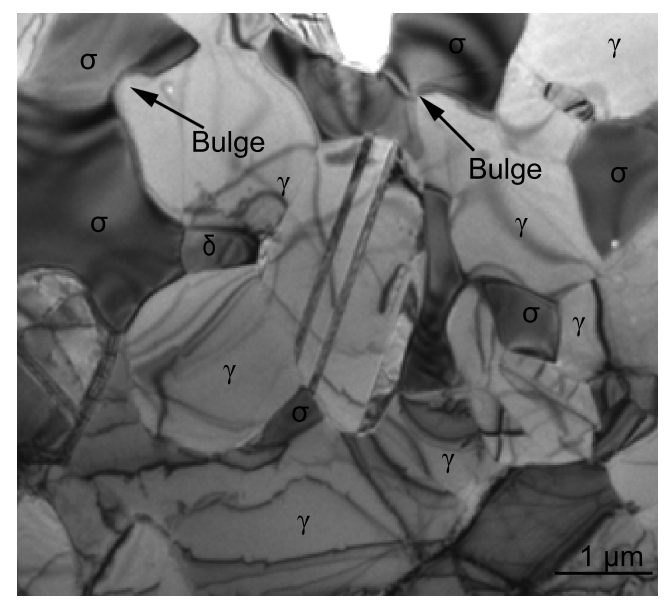

Fig. 6 TEM micrograph for the cold-rolled DSS after the second aging treatment at $850{ }^{\circ} \mathrm{C}$ showing the mechanism of $\delta$-phase decomposition into $\sigma$-phase precipitation and $\gamma$-phase transformation $\sigma$-phase precipitates, which is thought to be a typical character of the $\sigma$-phase precipitation in the microduplex structure. This unexpected novel character might be helpful for innovation of some technologies to further improve the mechanical properties of the micro-duplex structure. However, more studies will be required to elucidate that precipitation behavior in detail.

\section{Conclusions}

Micro-duplex structure of the fine equiaxed $\delta$ and $\gamma$-grains in $25 \mathrm{Cr}-7 \mathrm{Ni}-3 \mathrm{Mo}-0.2 \mathrm{~N}$ DSS could be obtained by the combination of the cold rolling process with $70 \%$ reduction in thickness and the subsequent aging treatment at $1000{ }^{\circ} \mathrm{C}$. During that aging treatment, $\delta \rightarrow \gamma$ transformation took place in association with the occurrence of the extensive recovery or a little recrystallization in $\delta$-grains. During the second aging treatment at $850{ }^{\circ} \mathrm{C}$ for the micro-duplex structure, most $\sigma$-phase nucleates along the $\delta / \gamma$ interfaces and grew along the interfaces into various morphologies of butterfly and granule around the $\delta$ - or $\gamma$-grains. However, neither eutectic character of the $\sigma$ phase morphologies nor the prior phases, such as isolated secondary austenite $\gamma_{2}$ and carbides, have been observed. Furthermore, it has been found that the $\gamma$-grain boundaries bulge not only into the $\delta$-grains as usual but also abnormally into the $\sigma$-phase precipitates.

\section{Acknowledgements}

The authors are very grateful to the financial support by the Project of Investigation on Fundamental Issues of Stainless Steels from Shenyang National Laboratory for Materials Science (SYNL), Institute of Metal Research (IMR), Chinese Academy of Sciences (CAS) (No. KGCX2-YW-221). Both Dalian Huarui Heavy Industry Group Co., LTD. and Heval Hengdian Machinery Co., LTD. CNNC are sincerely appreciated for their supplying materials of the experimental samples.

\section{REFERENCES}

[1] R. Lula, Duplex stainless steels, American Society for Metals, Ohio, 1983, p. 283.

[2] J.O. Nilsson, Mater. Sci. Technol. 8 (1992) 685.

[3] F. Xue, Z.X. Wang, G. Shu, W. Yu, H.J. Shi and W. Ti, Nucl. Eng. Des. 239 (2009) 2217.

[4] Z.X. Wang, F. Xue, W.H. Guo, H.J. Shi, G.D. Zhang and G. Shu, Nucl. Eng. Des. 240(2010) 2538.

[5] J.O. Nilsson, in: Proceedings Duplex Stainless Steel 97, Maastricht, Holanda, 1997, p.73.

[6] J.Charlesa, P. Chemelleb, in: 8th Duplex Stainless Steels conference, Beaune, France, October13-15, 2010.

[7] I. Calliari, M. Zanesco and E. Ramous, J. Mater. Sci. 41 (2006) 7643.

[8] M. Pohl, O. Storz and T. Glogowski, Mater. Charact. 58 (2007) 65. 
[9] Y. Ahn and J. Kang, Mater. Sci. Technol. 16 (2000) 382.

[10] T. Chen, K. Weng and J. Yang, Mater. Sci. Eng. A 338 (2002) 259.

[11] H.M. Ezuber, A.E. Houd and F.E. Shawesh, Desalination 207 (2007) 268.

[12] D. E. Villanueva, F. Junior, R. Plaut and A. Padilha, Mater. Sci. Technol. 22 (2006) 1098.

[13] J. Elmer, T. Palmer and E.D. Specht, Metall. Trans. A 38 (2007) 464.

[14] R. Badji, M. Bouabdallah, B. Bacroix, C. Kahloun, K. Bettahar and N. Kherrouba, Mater. Sci. Eng. A 496 (2008) 447.

[15] M. Martins and L.C. Casteletti, Mater. Charact. 60 (2009) 792.

[16] J.O. Nilsson, P. Kangas, A. Wilson and T. Karlsson,
Metall. Trans. A 31 (2000) 35.

[17] I. Calliari, K. Brunelli, M. Zanellato, E. Ramous and R. Bertelli, J. Mater. Sci. 44 (2009) 3764.

[18] Y. Fang, Z. Liu, W. Xue, H. Song and L. Jiang, ISIJ Int. 50 (2010) 286.

[19] T. Liang, X.H. Kang, X.Q. Hu and D.Z. Li, Acta Metall. Sin. 47 (2011) 921. (in Chinese)

[20] X.F. Wang, W.Q. Chen and H.G. Zheng, Iron Steel 44(1) (2009) 63.(in Chinese)

[21] T. Maki, T. Furuhara and K. Tsuzaki, ISIJ Int. 41(2001) 571.

[22] G. Fargas, N. Akdut, M. Anglada and A. Mateo, ISIJ Int. 48 (2008) 1596.

[23] J. Cabrera, A. Mateo, L. Llanes, J. Prado and M. Anglada, J. Mater. Process. Technol. 143 (2003) 321. 